\title{
PULMONARY ARTERIAL PRESSURE IN ACYANOTIC CONGENITAL HEART DISEASE
}

\author{
BY \\ R. J. SHEPHARD \\ From the Cardiac Department, Guy's Hospital \\ Received May 10, 1954
}

Cardiac catheterization allows an investigation of the relationships between pressure and flow in the pulmonary circulation, and the findings in patients with a left-to-right shunt are assuming increasing importance with the development of controlled intracardiac surgery. A number of workers have now reported catheterization findings in cases of patent ductus arteriosus (Dexter et al., 1950; Wood, 1950; Taylor et al., 1950; Storstein et al., 1952; Lurie et al., 1952; and Voci et al., 1951). It has been possible to collect instances of cases showing severe pulmonary hypertension, sometimes dating from an early age (Cosh, 1953, and Hultgren et al., 1953), and in most series a proportion of the cases show some degree of hypertension. However, there is no real agreement concerning the æatiology of hypertension in patent ductus arteriosus or the relative incidence when compared with cases presenting other types of left-to-right shunt.

The present paper records the experience of the cardiac department of Guy's Hospital with 24 cases of patent ductus arteriosus submitted to cardiac catheterization. Pressure/flow relationships in the pulmonary circulation have been given particular study. The results are compared with observations on a further group of acyanotic patients comprising 17 cases of atrial septal defect (one repeated after the lapse of two years) and 14 cases of ventricular septal defect.

\section{MethoDS}

The technique of catheterization employed in this hospital has already been described (Holling and Zak, 1950) and it is therefore only necessary to refer to a few special points of procedure.

Pressure Recording. Earlier measurements were made with a Hamilton manometer, mean pressures being ascertained either by planimetric integration or by use of a saline manometer. However, over the last two years both phasic and mean pressures have been recorded by means of a capacitance electromanometer (Southern Instruments Limited, Camberley). The basic physical principles governing the use of this type of manometer have been reviewed by Hansen (1949), and it is only necessary to add that in the experience of this department it is a satisfactory instrument from the practical as well as the theoretical standpoint.

Flow Rates. Flow rates in both the systemic and pulmonary circulations have been calculated by use of the direct Fick procedure. Although this method has been criticised recently, particularly in the United States (Visscher and Johnson, 1953), it remains for most workers the standard against which other techniques are calibrated, for it gives within clearly defined limits of accuracy the value that is of prime clinical interestthe mean resting flow.

In patients with a left-to-right shunt there are certain special difficulties, for where the pulmonary arteriovenous oxygen difference is small, a slight error in the measurement of either arterial or venous oxygen saturation can give rise to a considerable error in the calculated rate of flow. This is particularly apparent in cases of patent ductus arteriosus, for in this group mixing of blood in the main pulmonary artery is often incomplete, one lung receiving blood of higher oxygen content than the other (Fig. 1).

As would be expected from the anatomy of the patent ductus, it is usually the left branch of the pulmonary artery that shows the higher oxygen saturation, the average difference in the present series being 
1.04 per cent (that is, about 0.2 vols. oxygen $/ 100 \mathrm{ml}$., assuming the total hæmoglobin level to be within normal limits). Other workers, particularly Eppinger et al. (1941), have also drawn attention to this factor of incomplete mixing, which can add a large error to basic laboratory inaccuracies in the measurement of oxygen saturation. To overcome this difficulty, wherever possible, samples have been obtained in the present series from both branches of the pulmonary artery, and the mean oxygen content of the two samples has been used in the calculation of pulmonary flow.

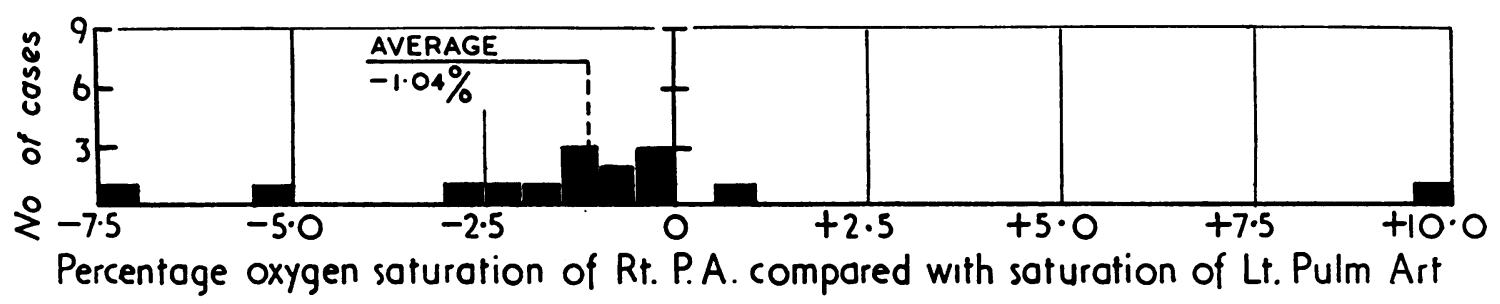

FIG. 1.-Histogram showing distribution of difference in oxygen saturation between right and left pulmonary arteries in 15 cases of patent ductus arteriosus. Note the tendency to a lower percentage saturation in the right pulmonary artery.

Catheter Manipulations. The success of catheter manipulation compares satisfactorily with other series. In only two of the cases of patent ductus, both investigated near the start of the series, did it prove impossible to enter the pulmonary artery. It was entered in all the cases of ventricular septal defect. However, in the group of atrial septal defects, the proportion of partial failures was rather higher, the pulmonary artery being entered in only 12 out of 18 catheterizations. Two of the cases in which difficulty was experienced were very young children; in others, there appeared to be a very large atrial septal defect and the tip of the catheter repeatedly passed through this defect instead of entering the right ventricle.

\section{Selection of Cases}

Many of the cases submitted to catheterization showed a somewhat atypical clinical picture, so that before passing to an examination of the pressure flow relationships, it is necessary to consider the grounds on which the diagnoses were reached in the various patients.

(a) Patent Ductus Arteriosus. In 7 of the 24 cases, direct confirmation of the diagnosis was obtained by passage of the catheter through the ductus in the typical position described by Bouchard (1951). It is probably fair to add that this evidence was obtained only in the more recent cases, and that in future the proportion may be rather greater than these figures would suggest.* Most of the others have been confirmed by operation, but even where this support is not yet available, there is evidence of a large left-to-right shunt into the pulmonary artery, the average difference in oxygen content between right ventricular and pulmonary arterial samples being $2.3 \mathrm{ml} . / 100 \mathrm{ml}$. (Fig. 2). An oxygen difference of $0.5 \mathrm{ml} . / 100 \mathrm{ml}$. is generally accepted as being significant at this level (Holling and Zak, 1950; Storstein et al., 1952), and only one case fails to achieve this figure. The patient in question was a small child, and it was necessary to introduce the catheter via the left long saphenous vein: it did not prove possible to advance the catheter beyond the proximal part of the pulmonary trunk, and it may not therefore have reached a suitable position to obtain samples significantly contaminated by the ductus stream. However, in this particular patient the diagnosis has since been confirmed by operation.

(b) Atrial Septal Defect. In 11 of the 17 patients, direct passage of the catheter through an atrial septal defect was obtained. The others showed a large difference in oxygen content between the caval and atrial specimens, the average difference for the group being $3.0 \mathrm{ml} . / 100 \mathrm{ml}$. Mixing errors in the right atrium may be considerable, and an oxygen difference of $2.0 \mathrm{ml} . / 100 \mathrm{ml}$. is necessary to provide conclusive evidence of an inter-atrial shunt. Two patients fall a little short of this limit, but in one the diagnosis was confirmed by direct passage of the catheter through the defect, and in the other it was based on good clinical grounds. Two other cases show virtually no oxygen difference. In one of these (Case 0352) this is due to a reversal of the shunt. The other (Case 0777) was shown to have an inter-atrial communication by passage of the catheter, but since this appeared to be unimportant from the hæmodynamic point of view, it has been excluded from the present analysis.

\footnotetext{
* Figures at time of publication: direct entry in 10 of 28 cases.
} 
The oxygen content of the right atrial sample may of course be increased by conditions other than an atrial septal defect, but these are less common. Careful study of the atrial pressure record helped to eliminate " external" causes of an increased oxygen content of the atrial sample, such as a ventricular septal defect with tricuspid incompetence. Causes within the atria are less easy to distinguish with certainty, although if the shunt is large, an atrial septal defect is by far the most likely diagnosis.

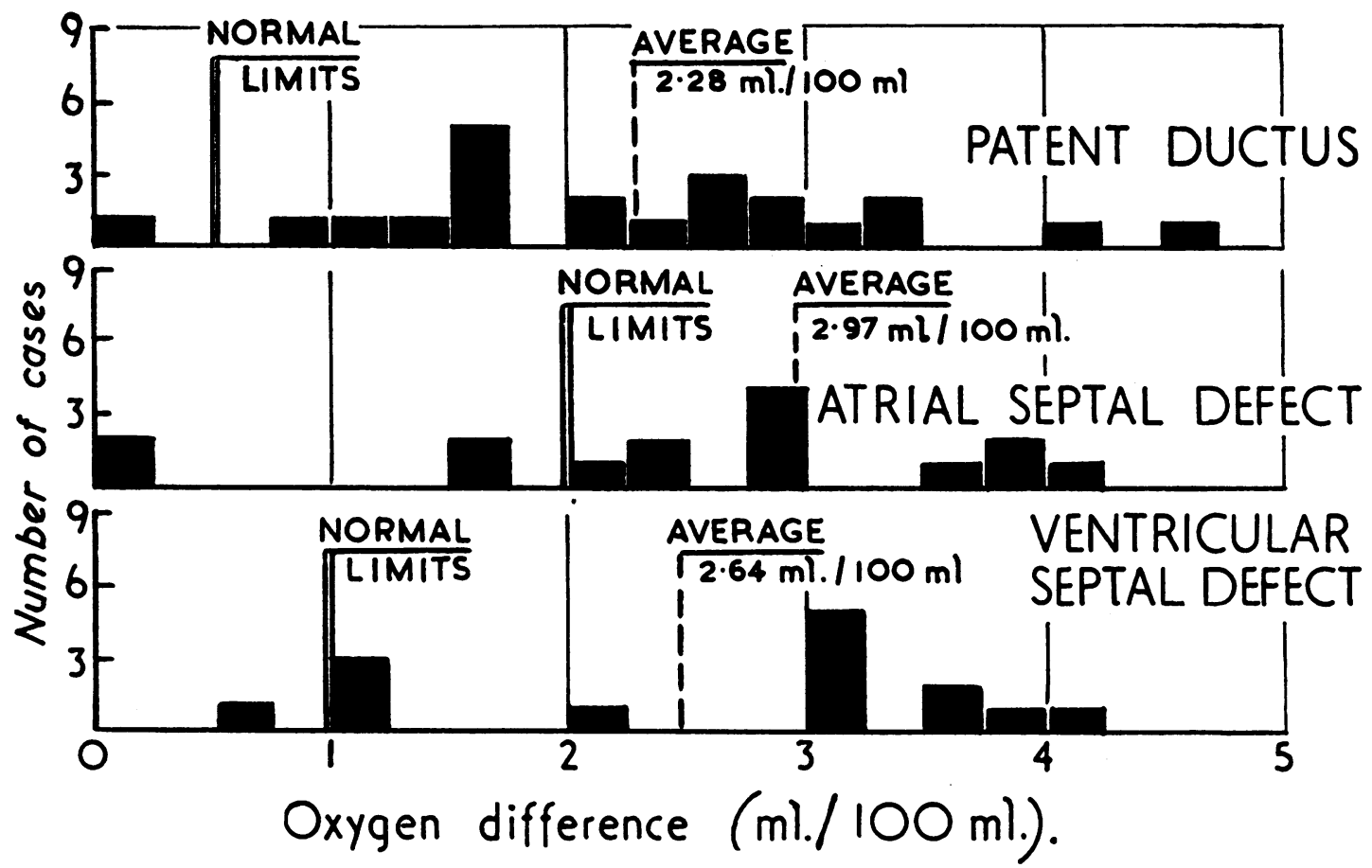

Fig. 2.-Magnitude of oxygen difference observed with left-to-right shunts at different levels in the present series. Note that one case of patent ductus arteriosus, four cases of atrial septal defect, and one case of ventricular septal defect fall within normal limits.

(c) Ventricular Septal Defect. The diagnosis has rested mainly on the finding of a large left-to-right ventricular shunt, the average increase in oxygen content being $2.6 \mathrm{ml} . / 100 \mathrm{ml}$. A difference of $1.0 \mathrm{ml} . / 100 \mathrm{ml}$. is usually accepted as significant here, and only one of the 14 patients falls below this limit. In three of the more recent cases, direct confirmation has been obtained by entry of the aorta through the septal defect, and in one other the diagnosis has been confirmed at subsequent autopsy. For six of the remaining ten, some supporting evidence has been obtained from a satisfactory correlation between right ventricular and systemic systolic pressures (Fig. 3). In the 4 cases where the catheter evidence is limited to the finding of an increased oxygen content in the right ventricular sample there is a possibility of confusion with (1) patent ductus with pulmonary regurgitation, or (2) an atrial shunt with incomplete mixing at an atrial level. However, all four show large shunts at a ventricular level with no suggestion of other changes in the right atrial or pulmonary artery samples, and the clinical evidence gives strong support to the diagnosis of ventricular septal defect.

\section{Normal Standards of Pressure and Flow}

(1) Pulmonary Arterial Pressure. A fair number of catheterizations have now been carried out on normal subjects, and the normal pressure relationships during this investigation are therefore known within clearly defined limits. Recently Fowler et al. (1953) were able to collect 58 reported cases, and adding 18 observations of their own gave the normal range of pulmonary arterial pressure as 11-29 mm. $\mathrm{Hg}$ systolic, 4-13 mm. $\mathrm{Hg}$ diastolic, and 8-19 $\mathrm{mm}$. $\mathrm{Hg}$ mean, all values being referred 
to a line $10 \mathrm{~cm}$. anterior to the spine. In applying these results to clinical material, it must be remembered that during catheterization, the average cardiac patient is subjected to a very different pattern of emotional stress from that experienced by healthy university students, for the latter, understand the procedure more fully and know that nothing hangs upon the result of the investigation

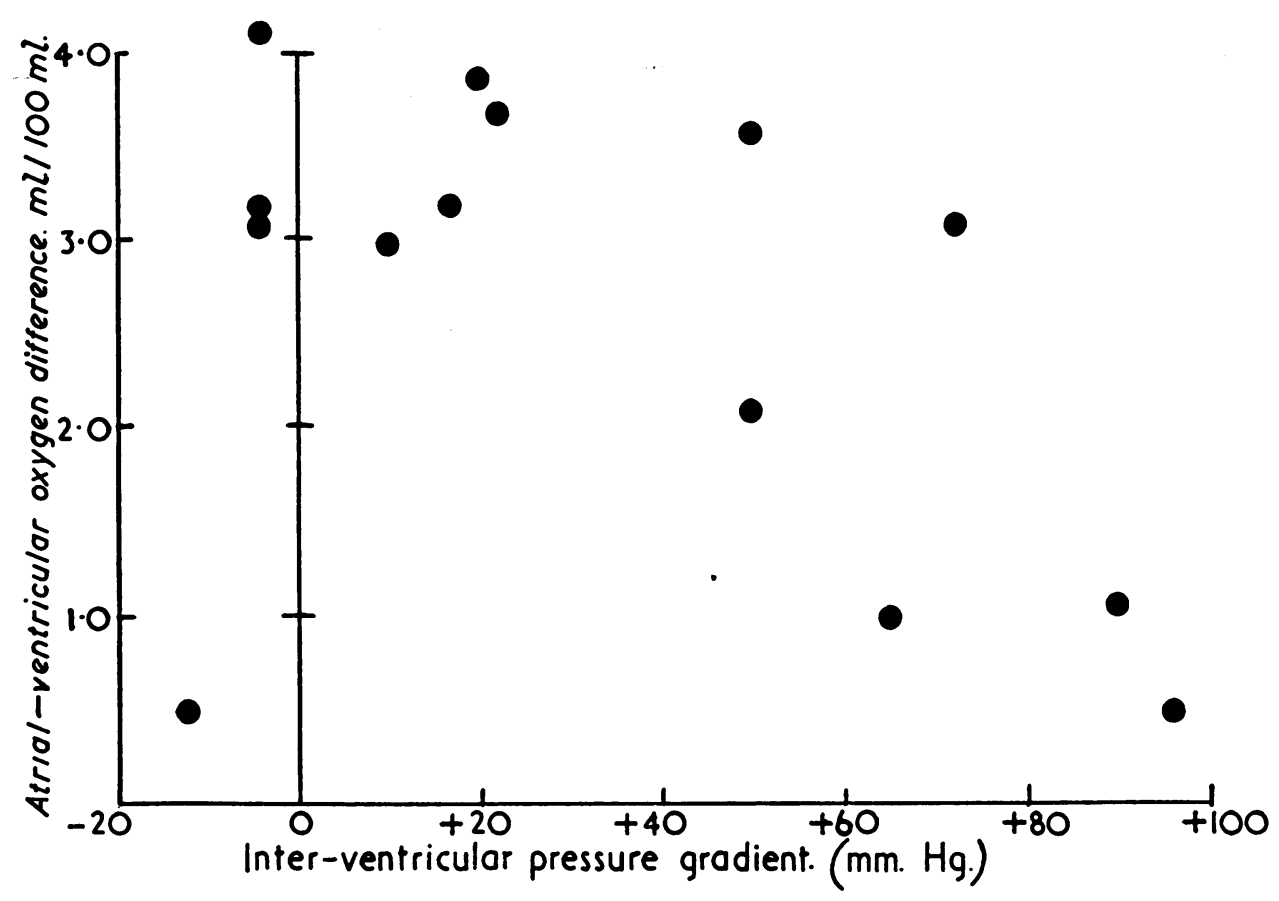

Fig. 3.-Relationship between atrial-ventricular oxygen difference and the inter-ventricular pressure gradient in cases of ventricular septal defect.

Not a great deal is known of the influence of the emotions upon the pulmonary arterial pressure, although the current impression is that the pulmonary vessels are little affected by the central nervous system except in left-sided heart failure (Hickham et al., 1948) and comparatively stable levels of pressure might therefore be expected. In a few cases the patient has been asked to carry out mathematical exercises of varying complexity but this has had little influence on the pulmonary artery pressure. Further, in patients who have been recatheterized, very similar levels of pressure have been observed. Thus it seems unlikely that the pulmonary arterial pressure is much increased by emotional factors in these cases. In the present series pressures have been referred to the midaxillary line, and note has been taken of severe cases of pulmonary hypertension (systolic pressure exceeding $80 \mathrm{~mm}$. $\mathrm{Hg}$ ), moderate cases (systolic pressure greater than $45 \mathrm{~mm}$.), and slight cases (systolic pressure greater than $30 \mathrm{~mm}$.).

(2) Pulmonary Flow. In order to allow a comparison of the relative rates of flow in the different subjects, some method of standardizing the results is needed. The flow has therefore been expressed as a ratio to the total expected value in a normal subject of the same age. A ratio of this type cannot be applied satisfactorily to cyanotic patients, for in such cases the height and weight are often below average; however, in the acyanotic patients where general development is relatively normal the pulmonary flow ratio probably affords a better means of comparison than the flow rate per square metre of body surface, since the latter is known to vary somewhat with age. Normal flow values for the different ages have been calculated as suggested by Deuchar and Knebel (1952).

(3) Pulmonary Arteriolar Resistance. This gives a numerical expression to the resistance to flow through the pulmonary vessels; to derive this quantity it is necessary to know the pulmonary 
flow (in absolute units) and the pressure gradient from the pulmonary artery to the left atrium. The value thus determined includes also the resistance of the small pulmonary arteries and the pulmonary capillaries; however, their contribution to the total resistance is relatively small, and the figure obtained is largely an expression of the condition of the pulmonary arterioles.

Normal standards of pulmonary arteriolar resistance vary greatly according to the method of calculation employed. American authors, such as Dexter et al. (1950), quote values as low as 45-90 dynes/sec./cm. ${ }^{5}$, whereas Deuchar and Knebel (1952) give values of 200-400 dynes/sec./cm. ${ }^{5}$. The principal difficulty is the estimation of the left atrial pressure, which in many instances cannot be determined directly. The use of the pulmonary capillary pressure (Hellems, 1948; Lagerlof and Werkö, 1949) has been suggested as an approximate measure, but Dow et al. (1950) point out that this value may differ by as much as $4 \mathrm{~mm}$. $\mathrm{Hg}$ from the true atrial pressure-that is by a sufficient margin to produce an error of up to 50 per cent in the calculations. Deuchar and Knebel suggest the assumption of a left atrial pressure approximating to zero, but this gives rise to a systematic error in the results, since the normal left atrial pressure is now recognized to be at least $5 \mathrm{~mm}$. Hg (Cournand et al., 1950; Fowler et al., 1953). While recognizing that no method other than the direct measurement of left atrial pressure is completely satisfactory, it seems preferable where this value is not available to adopt the accepted normal value of $5 \mathrm{~mm}$. $\mathrm{Hg}$. On this basis, and using the normal standards of flow and pressure given for the pulmonary artery by Deuchar and Knebel (1952), it is possible to calculate the expected pulmonary arteriolar resistance at different ages as follows.

$\begin{array}{ll}\text { Age } 5 & 240 \text { dynes } / \mathrm{sec} . / \mathrm{cm} . \\ \text { Age } 10 & 180 \text { dynes } / \mathrm{sec} . / \mathrm{cm} . \\ \text { Age } 20 & 120 \text { dynes } / \mathrm{sec} . / \mathrm{cm} .\end{array}$

\section{The Pulmonary Arterial Pressure in Acyanotic Heart Disease}

(1) Patent Ductus. Ten of the 22 cases have a systolic pressure that falls within normal limits (Table I), and many of the remainder fall only just outside the upper limit of normality. Three of the 6 cases with high pressure have unfortunately saline manometer readings only, and are therefore recorded as mean pressures. The suggestion that there is a particular elevation of the diastoic pressure in many cases of patent ductus, due to continued inflow through the ductus in the diastolic phase, is supported by the present figures. In 10 of 17 , the diastolic pressure is greater than normal, and this increase is responsible for the relatively normal pulmonary arterial pulse pressure observed in most patients.

(2) Atrial Septal Defect. A high proportion of these cases show high systolic pressure, particularly if account is taken of the fact that 2 of the 5 showing a normal pressure have a very small shunt and may in fact represent anomalies of pulmonary venous drainage rather than true atrial septal defects. All these with increased systolic pressure show some increase also in the diastolic pressure, but despite this there is a tendency to widening of the pulse pressure.

(3) Ventricular Septal Defect. In this group, the right ventricular systolic pressure corresponds fairly closely with the left ventricular pressure, unless the defect as indicated by the atrio-ventricular oxygen difference is small (Fig. 3). Further, unless there is some coincident pulmonary stenosis, this pressure is transmitted directly to the pulmonary artery. Thus a marked elevation of the pulmonary arterial pressure is to be expected, and is found in 10 of the 14 cases. In one of the remaining 4 (Case O279) the size of the defect, as judged from the magnitude of the shunt, is small; in one other (Case O655) there is also a stenosis of the pulmonary valve, although this is of insufficient degree to prevent a left-to-right shunt. As in the previous group, all cases with an increase in systolic pressure show also a rise in diastolic pressure, with some tendency to a widening of the pulse pressure. 
TABLE I

Pulmonary Arterial Pressures (systolic and diastolic) in Patients With left to Right Shunts

\begin{tabular}{|c|c|c|c|c|c|c|c|c|c|c|c|}
\hline \multicolumn{3}{|c|}{$\begin{array}{l}\text { No rise of systolic } \\
\text { pressure: } 0-30 \mathrm{~mm} . \mathrm{Hg}\end{array}$} & \multicolumn{3}{|c|}{$\begin{array}{l}\text { Slight rise of systolic } \\
\text { pressure: } 31-45 \mathrm{~mm} . \mathrm{Hg}\end{array}$} & \multicolumn{3}{|c|}{$\begin{array}{l}\text { Moderate rise of systolic } \\
\text { pressure: } 45-80 \mathrm{~mm} \text {. } \mathrm{Hg}\end{array}$} & \multicolumn{3}{|c|}{$\begin{array}{l}\text { Severe rise of systolic } \\
\text { pressure: greater than } \\
80 \mathrm{~mm} . \mathrm{Hg}\end{array}$} \\
\hline $\begin{array}{l}\text { Case } \\
\text { No. }\end{array}$ & $\underset{\text { sex }}{\text { Age and }}$ & Pressure & $\begin{array}{l}\text { Case } \\
\text { No. }\end{array}$ & $\underset{\text { sex }}{\text { Age and }}$ & Pressure & $\begin{array}{l}\text { Case } \\
\text { No. }\end{array}$ & $\underset{\text { sex }}{\text { Age and }}$ & Pressure & $\begin{array}{c}\text { Case } \\
\text { No. }\end{array}$ & $\begin{array}{l}\text { Age and } \\
\text { sex }\end{array}$ & Pressure \\
\hline $\begin{array}{l}\text { IPJA } \\
\text { O304 } \\
\text { P277 } \\
\text { P275 } \\
\text { P312 } \\
\text { O413 } \\
\text { O280 } \\
\text { P286 } \\
\text { CB30 } \\
\text { IPDZ }\end{array}$ & $\begin{array}{l}\text { F6 } \\
\text { F8 } \\
\text { F8 } \\
\text { M21 } \\
\text { F5 } \\
\text { F8 } \\
\text { M27 } \\
\text { M14 } \\
\text { F60 } \\
\text { M18 }\end{array}$ & $\begin{array}{l}22 / 8 \\
28 / 23 \\
21 / 12 \\
15 / 4 \\
27 / 5 \\
23 / 12 \\
(18) \S \\
21 / 11 \\
23 / 10 \\
26 / 9\end{array}$ & $\begin{array}{l}\text { H279 } \\
\text { O418 } \\
\text { O849 } \\
\text { O781 } \\
\text { O391 } \\
\text { P226 }\end{array}$ & $\begin{array}{l}\quad(a) l \\
\text { F18 } \\
\text { F7 } \\
\text { F4 } \\
\text { F5 } \\
\text { F5 } \\
\text { F5 }\end{array}$ & \begin{tabular}{|} 
atent Duc \\
$32 / 15$ \\
$38 / 27$ \\
$45 / 27$ \\
$33 / 19$ \\
$31 / 17$ \\
$43 / 30$
\end{tabular} & $\begin{array}{l}\text { tus Arter } \\
\text { O621 } \\
\text { P255 } \\
\text { P308 } \\
\text { O423 } \\
\text { P311 } \\
\text { O982 }\end{array}$ & \begin{tabular}{|l|} 
osus \\
F11 \\
F7 \\
F5 \\
F13 \\
F2 \\
F12
\end{tabular} & $\begin{array}{l}(45) \S \\
(45) \\
49 / 30 \\
(45) \\
53 / 39 \\
61 / 40\end{array}$ & & & \\
\hline $\begin{array}{l}\text { O305 } \\
\text { IPBE } \\
\text { O291 } \\
\text { P223 } \\
\text { O626 }\end{array}$ & $\begin{array}{l}\text { F9 } \\
\text { M33 } \\
\text { M7 } \\
\text { M12 } \\
\text { M7 }\end{array}$ & $\begin{array}{l}16 / 7 \\
23 / 9 \\
30 / 5 \\
25 / 10 \\
21 / 6\end{array}$ & 0125 & $\begin{array}{l}(b) \\
\text { F9 }\end{array}$ & $\begin{array}{l}\text { Atrial Sept } \\
44 / ?\end{array}$ & $\begin{array}{l}\text { al Defec } \\
\text { O900 } \\
\text { O900 } \\
\text { P227 }\end{array}$ & $\begin{array}{l}\text { F42 } \\
\text { F44* } \\
\text { M27 }\end{array}$ & $\begin{array}{l}58 / 24 \\
74 / 29 \\
(64)\end{array}$ & $\begin{array}{l}\text { P176 } \\
\text { O689 } \\
\text { O352 }\end{array}$ & $\begin{array}{l}\text { F35 } \\
\text { F36 } \\
\text { M9 }\end{array}$ & $\begin{array}{l}140 / 62 \\
103 / 42 \\
130 / 85\end{array}$ \\
\hline $\begin{array}{l}\text { O655 } \\
\text { O279 }\end{array}$ & $\begin{array}{l}\text { F19 } \\
\text { F16 }\end{array}$ & $\begin{array}{l}30 / 8 \\
18 / 5\end{array}$ & $\begin{array}{l}0545 \\
\text { P233 }\end{array}$ & $\begin{array}{l}\text { (c) Ve } \\
\text { F15 } \\
\text { M7 }\end{array}$ & $\begin{array}{c}\text { icular } S \\
33 / 18 \\
37 / 20\end{array}$ & $\begin{array}{l}\text { eptal De } \\
\text { O163 } \\
\text { O991 } \\
\text { IPRP }\end{array}$ & $\begin{array}{l}\text { M3 } \\
\text { M9 } \\
\text { M3 }\end{array}$ & $\begin{array}{l}57 / 27 \\
55 / 25 \\
73 / 47\end{array}$ & \begin{tabular}{|l|} 
O606 \\
O142 \\
O467 \\
O634 \\
CB23 \\
O164 \\
1077 \\
\end{tabular} & $\begin{array}{l}\text { F18 } \\
\text { M13 } \\
\text { F48 } \\
\text { F11 } \\
\text { F18 } \\
\text { M15 } \\
\text { F22 } \\
\end{array}$ & $\begin{array}{r}102 / 61 \\
83 / 35 \\
128 / 58 \\
93 / 40 \\
107 / 68 \\
95 / 35 \\
105 / 57 \\
\end{array}$ \\
\hline
\end{tabular}

* Repeat two years later.

$¥$ Associated moderate pulmonary stenosis.

$\S$ Where mean pressure only has been recorded, this is indicated in brackets.

\section{FORM OF MANOMETER RECORDS}

Before considering possible reasons for the low incidence of pulmonary hypertension in the patent ductus group, there are two further points concerning the pressure record that deserve attention.

Typical Ductus Pattern. Where the ductus is actually entered a typical pressure tracing may be obtained as the catheter passes through the ductus (Voci et al., 1951). The form of the pulmonary arterial tracing itself, however, which sometimes becomes rather irregular at the point of entry of the ductus stream, is not sufficiently characteristic to be pathognomonic of the presence of a patent ductus.

The Incidence of Relative Stenosis. A small pressure gradient across the pulmonary valve has been described in cases of atrial and ventricular septal defects with large left-to-right shunts, and has been attributed to a relative stenosis of the valve. The present results show gradients of $0-5 \mathrm{~mm}$. $\mathrm{Hg}$ in 28 cases, $5-10 \mathrm{~mm}$. in 5 cases, $10-15 \mathrm{~mm}$. in 5 cases, and $15-20 \mathrm{~mm}$. in 3 cases. However, 18 of the patients with a gradient have a patent ductus, so this effect cannot be attributed to an increased flow through the pulmonary orifice. The change is in any case gradual in type, and totally unlike the sudden drop of pressure found at a narrowed valve-and a more probable explanation of the gradient lies in changes of elasticity in the walls of the pulmonary artery associated with post-valvular dilatation. It is difficult to state with certainty the gradient necessary for a diagnosis of organic stenosis, since even at autopsy slight degrees of stenosis are hard to assess. Some would take $20 \mathrm{~mm}$. $\mathrm{Hg}$ as the maximum that can be attributed to factors other than stenosis, although it is probably more satisfactory to be guided by the form of the manometer record, and particularly by the sharpness of the pressure change. 
Factors Influencing the Pulmonary Arterial Pressure

In an attempt to elucidate the reasons for the lower incidence of pulmonary arterial hypertension in the patent ductus group, various factors that may influence this pressure will be compared in the different forms of acyanotic congenital heart disease.

(a) Size of Shunt. Where the rate of flow through the pulmonary circulation is only moderately increased, a passive fall in pulmonary arteriolar resistance can occur, and this change is often sufficient to maintain a fairly constant pulmonary arterial pressure. However, it has been shown experimentally that where the flow is increased above a critical level of about three times the resting flow (Riley et al., 1948) a rise of pressure typically occurs. Thus if the size of the left-to-right shunt is smaller in the patent ductus group, this may of itself explain the lower incidence of hypertension.

To examine this point, the pulmonary flow ratio (P.F.R.) has been calculated for each patient. To illustrate the results graphically, this value has been plotted against the observed pulmonary arterial systolic pressure (Fig. 4). The average P.F.R. in each of the three groups is very similar-

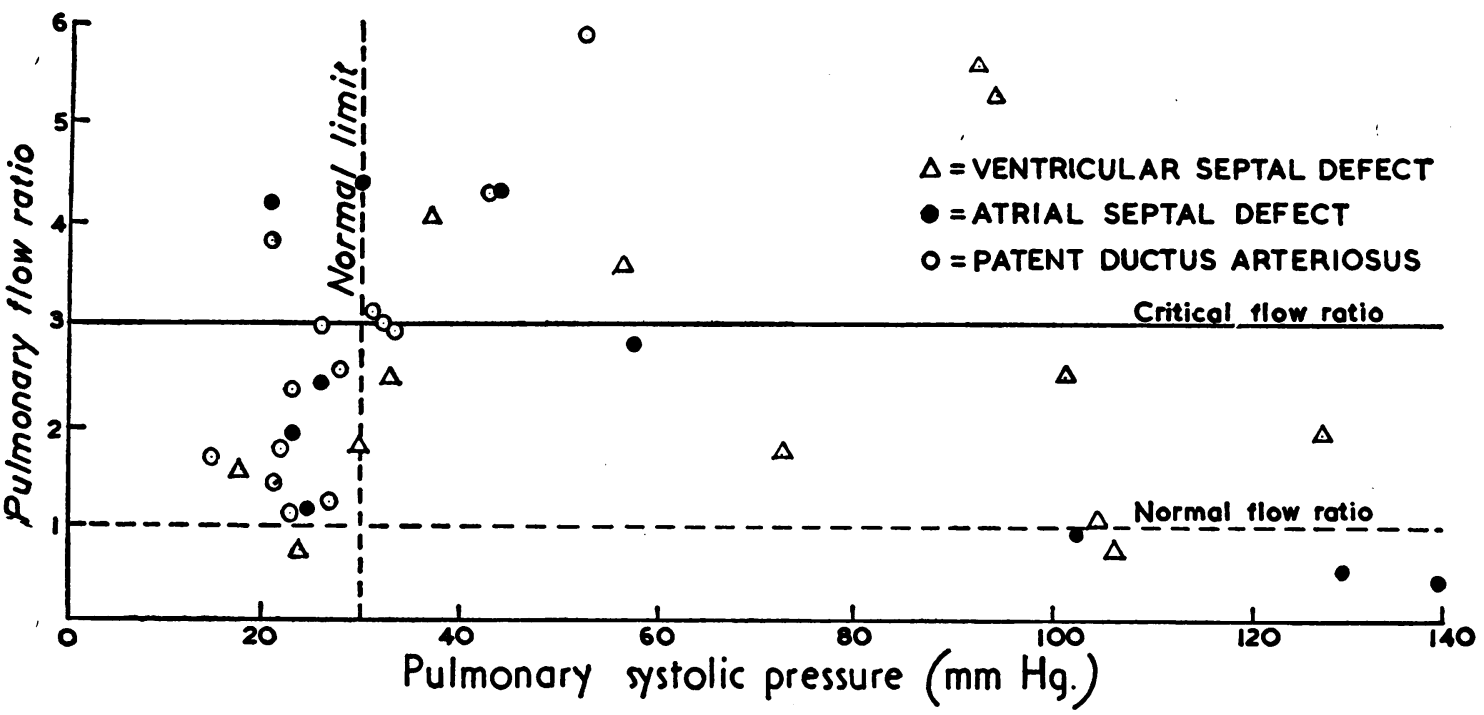

FIG. 4.-Relationship between pulmonary arterial systolic pressure and pulmonary flow ratio. Note that a normal pulmonary arterial pressure is typically associated with a flow ratio of less than the critical value of three times the normal flow. Where the ratio exceeds 3.0 , the pressure is in most cases increased.

patent ductus arteriosus $2 \cdot 71$ to $1 \cdot 0$, atrial septal defect 2.43 to $1 \cdot 0$, and ventricular septal defect 2.78 to $1 \cdot 0$. Further, the proportion with a P.F.R. exceeding the critical value of 3.0 is not very different in the three groups: patent ductus arteriosus $6 / 21$, atrial septal defect $3 / 12$, and ventricular septal defect 5/14. The general correlation between the P.F.R. and the level of pulmonary systolic pressure is not very close. However, it can be seen that in 13 of 15 cases with normal pressures, the P.F.R. is less than the critical value of 3.0. Further, there is some elevation of pressure in all except two of the cases where the P.F.R. is greater than $3 \cdot 0$. However, it will be noted that in 5 of 7 cases where the systolic pressure exceeds $100 \mathrm{~mm}$. Hg, the P.F.R. is less than unity. Thus although the large size of the left-to-right shunt furnishes some explanation of a number of the cases of moderate hypertension in all three groups, the most severe cases had at the time of the investigation a flow that was actually less than the normal value. This agrees well with radiological appearances, for such patients show typically a gross enlargement of the main pulmonary vessels, but a diminution in density of the lung fields. The present size of the shunt cannot therefore be invoked as an explanation of severe hypertension. 
(b) Age of Patients. It is possible that the increase in pulmonary arterial pressure is a late response to a large left-to-right shunt. An age difference in the three groups would then produce corresponding differences in the incidence of hypertension. Examination of Table I does show a somewhat higher average age in the atrial septal defect group: patent ductus arteriosus, 12.3 years; atrial septal defect, 19.6 years; and ventricular septal defect, 15.6 years. Further, 4 of the 5 cases of atrial septal defect with moderate or severe hypertension have an age of 27 or over, the important exception being Case 0352, aged 9 years.

There does, therefore, seem to be some indication that the gross increase in pulmonary systolic pressure with atrial septal defect is seen mainly in the older age group, and many cases of patent ductus tend to be submitted for catheterization before this age is reached. However, evidence that the pressure increases with age in patent ductus arteriosus is less convincing since the one elderly case has normal pressures.*

(c) Pulmonary Arteriolar Resistance. Since the differing incidence of hypertension in the three groups of acyanotic heart disease cannot be accounted for in terms of differing sizes of shunt, differences in the resting level of pulmonary arteriolar resistance are to be expected.

Certain general observations may first be made. It is realized that the accuracy of the measurements of resistance hinges upon the normality of the left atrial pressure in acyanotic heart disease. Accurate knowledge is only available for the atrial septal defect group, and here our observations confirm the findings of Pedersen and Warburg (1952), for even with gross elevation of the pulmonary arteriolar resistance, the left atrial pressure is still normal. Thus there is little justification for the view that the increased resistances are an artefact produced by back pressure from the left atrium.

As might be expected, there is a fairly close relationship between both systolic and diastolic pressures and the level of pulmonary arteriolar resistance (Fig. 5 and 6). However, it is interesting

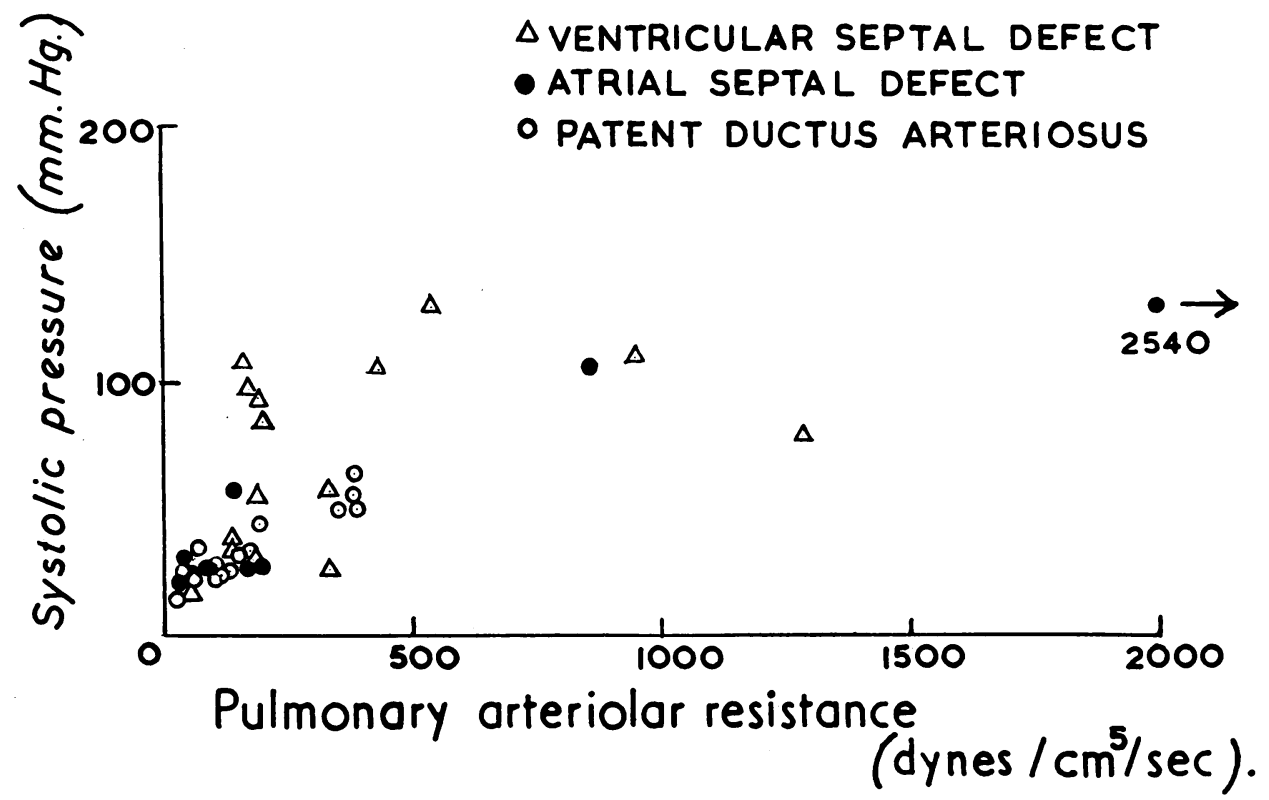

FIG. 5.-Relationship between pulmonary arteriolar resistance and pulmonary arterial systolic pressure. The cases of ventricular septal defect show less close correlation than the other forms of acyanotic heart disease.

* Since completion of this paper one other patent ductus in the older age group (Case 1110, age 45) has been catheterized. She was not a typical case of patent ductus, since there is no recorded history of other than a systolic murmur. Her pulmonary arterial pressures were moderately increased $(68 / 40 \mathrm{~mm}$. $\mathrm{Hg})$, and there was a closer correspondence between pulmonary and systemic diastolic pressures which may account for the absence of a continuous murmur (systemic pressures 132/54 mm. Hg). 


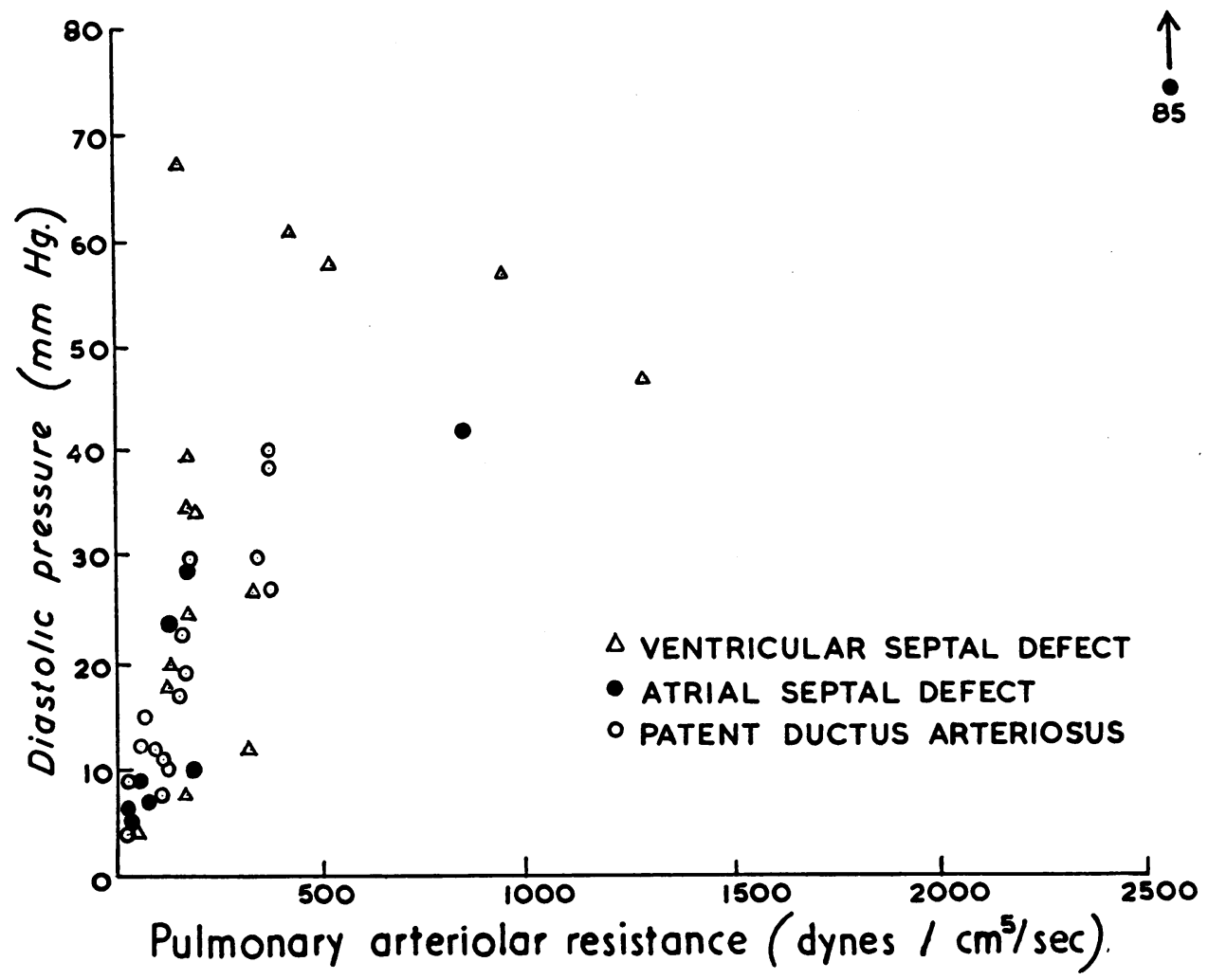

FIG. 6.-Relationship between pulmonary arteriolar resistance and diastolic pressure in the pulmonary artery. The cases of ventricular septal defect again show less correlation than other forms of acyanotic congenital heart disease.

to note that the correlation is much closer in the patent ductus and atrial septal defect groups than in the ventricular septal defect group. The probable explanation is that the pulmonary pressures in the latter group are influenced to a much greater extent by the pressure levels in the systemic circulation.

As with normal subjects, there is a tendency for resistance to fall through childhood to the age of about 20 years. This is seen particularly in the patent ductus group and there are some examples of atrial and ventricular septal defect showing a gross increase of resistance which do not fit in with this pattern. Owing to the normal tendency for resistance to vary with age, it is necessary to convert each observation to a percentage of the normal value for that age before an assessment is made of the incidence of increased resistance in the different groups of patients. Resistances standardized in this way are plotted against the P.F.R. in Fig. 7. It can be seen that a reduced flow is associated with an increased resistance, but where the flow is normal or increased there is no direct relationship between the present level of flow and the arteriolar resistance.

With Patent Ductus Arteriosus. The average resistance for this group is 97 per cent of normal, and most cases fall within the range of 50-150 per cent of normal, which probably represents the limits of error and personal variation. Two cases have a resistance of more than twice the normal value, and in both these a fairly large shunt is maintained despite the increase in resistance. In three others there is a considerable reduction in peripheral resistance to under $\mathbf{4 0}$ per cent of the normal value.

With Atrial Septal Defect. Satisfactory data has been obtained for 9 cases. Four fall within the range 50-150 per cent, two have very low resistances, and the remaining three are grossly increased, one to over 1200 per cent of the normal value. These increases in resistance are 


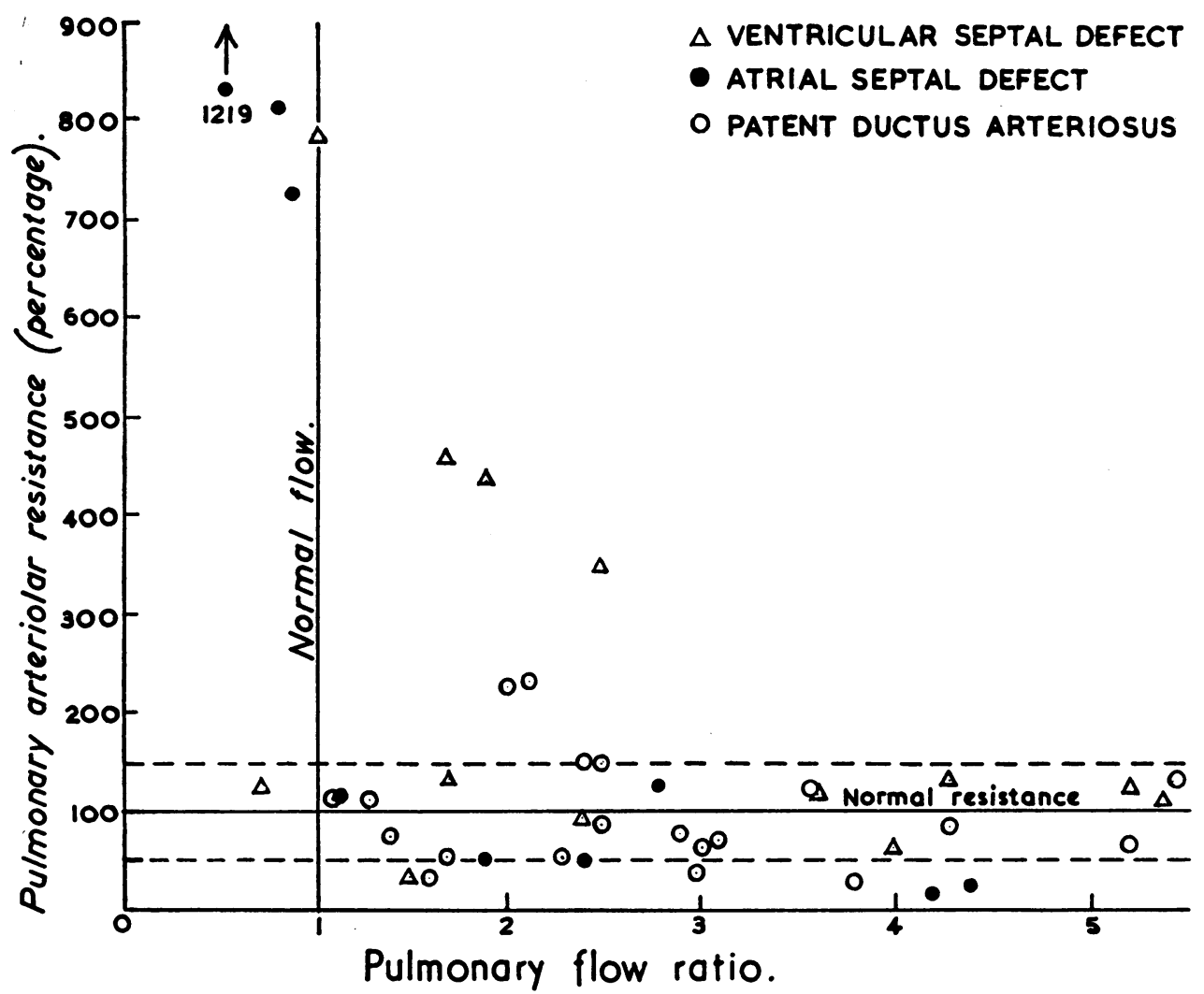

FIG. 7.-Relationship between pulmonary arteriolar resistance and pulmonary flow. It will be noted that a reduced flow is associated with an increased resistance, but where the flow is normal or increased there is little correlation between flow and resistance.

associated with a considerable reduction in flow despite high pulmonary pressures, and must represent a considerable narrowing of the pulmonary vessels.

With Ventricular Septal Defect. This group comprises 14 observations with an average resistance of 215 per cent of normal. Nine patients again fall within the range of 50-150 per cent of normal, one shows a considerable reduction in resistance, and four show marked increases in resistance, ranging from 343 to 783 per cent. This increase is not sufficient to cause a reduction of flow through the pulmonary circulation, except in one case.

It is thus possible for any patient with a left-to-right shunt to have a pulmonary arteriolar resistance above, below, or within normal limits, although the expectation of a normal resistance seems to be rather stronger in the patent ductus group. One factor contributing to this diversity of response to the shunt becomes apparent if the level of resistance is plotted against the age of the patient (Fig. 8). Thus 8 of 10 patients with grossly increased resistance are over the age of ten whilst 4 of 7 with grossly decreased resistance are under the age of ten. There is thus some justification for the view that in the young child the response to an increased flow is typically a decrease in peripheral resistance, probably passive in type. However, with the passage of the years, there is a progressive increase in resistance, until finally it may be grossly above the normal level. The explanation of this increase in resistance is probably a progressive anatomical change in the small vessels of the lungs.

(d) Arterial Saturation. Some support for a correlation between anatomical changes and changes in the level of peripheral resistance can be found in the degree of oxygenation of the blood achieved in the lungs. It is to be expected that those cases having severe anatomical changes and 


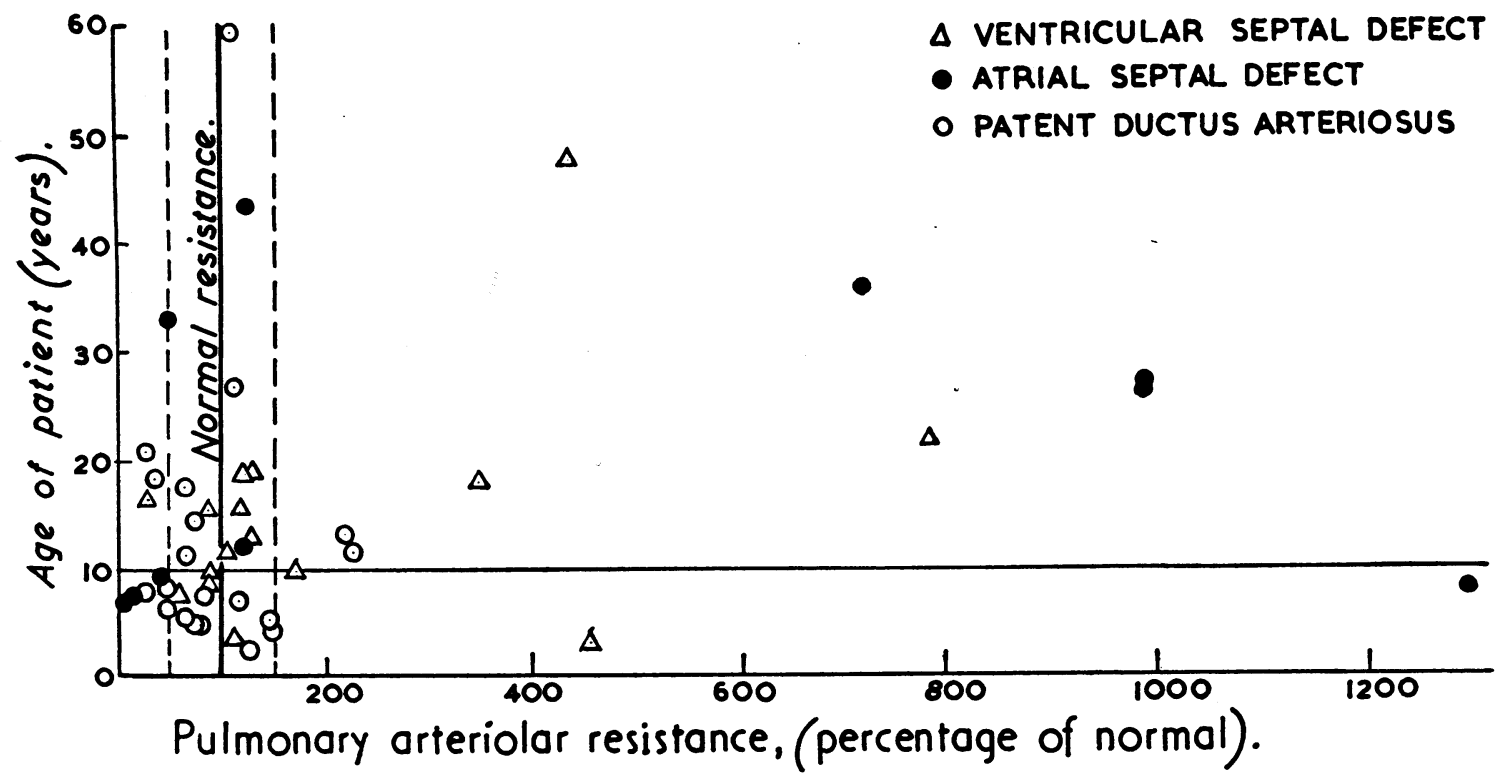

FIG. 8.-Relationship between age and the level of pulmonary arteriolar resistance. In all forms of acyanotic congenital heart disease there is a tendency for resistance to increase with age (see text).

therefore a high resistance will show some impairment of oxygenation. This concept is examined in Table II.

Four cases of patent ductus arteriosus show a reduction in arterial oxygen saturation, and in each the resistance was increased, the average for these four being considerably above the general level of resistance in the patent ductus group.

Four of the 9 cases of atrial septal defect in which the peripheral resistance can be calculated show a reduction in arterial saturation, and in at least three there is good reason to believe that this reduction was caused by pulmonary factors. In one (Case P227) changes in the pulmonary vessels were confirmed at post-mortem examination. In another (Case O352) direct intubation of the pulmonary veins confirmed the low saturation of blood leaving the lungs. In a third (Case O689) the arterial saturation was raised to a high normal level by the administration of oxygen-this change was considerably in excess of any effect that could be produced by the physical solution of

TABLE II

Pulmonary Arteriolar Resistance in cases showing Unsaturation of Pulmonary Venous or Arterial BLOOD

\begin{tabular}{|c|c|c|c|c|c|c|c|c|c|c|c|}
\hline \multicolumn{4}{|c|}{ Patent ductus arteriosus } & \multicolumn{4}{|c|}{ Atrial septal defect } & \multicolumn{4}{|c|}{ Ventricular septal defect } \\
\hline $\begin{array}{l}\text { Case } \\
\text { No. }\end{array}$ & $\begin{array}{l}\text { Sex and } \\
\text { age }\end{array}$ & $\begin{array}{c}\text { Percent- } \\
\text { age satu- } \\
\text { ration }\end{array}$ & $\begin{array}{c}\text { Resist- } \\
\text { ance } \\
(\%)\end{array}$ & $\begin{array}{l}\text { Case } \\
\text { No. }\end{array}$ & $\begin{array}{c}\text { Sex and } \\
\text { age }\end{array}$ & $\begin{array}{c}\text { Percent- } \\
\text { age satu- } \\
\text { ration }\end{array}$ & $\begin{array}{l}\text { Resist- } \\
\text { ance } \\
(\%)\end{array}$ & $\begin{array}{l}\text { Case } \\
\text { No. }\end{array}$ & $\begin{array}{c}\text { Sex and } \\
\text { age }\end{array}$ & $\begin{array}{l}\text { Percent- } \\
\text { age satu- } \\
\text { ration }\end{array}$ & $\begin{array}{c}\text { Resist- } \\
\text { ance } \\
(\%)\end{array}$ \\
\hline $\begin{array}{l}\text { O423 } \\
\text { O280 } \\
\text { CB30 } \\
\text { P311 }\end{array}$ & $\begin{array}{l}\text { F13 } \\
\text { M27 } \\
\text { F60 } \\
\text { M } 2\end{array}$ & $\begin{array}{l}93.5 \\
92.0 \\
90.0 \\
93.5\end{array}$ & $\begin{array}{l}221 \\
113 \\
109 \\
133\end{array}$ & $\begin{array}{l}\text { O689 } \\
\text { O352 } \\
\text { O900 } \\
\text { P227 }\end{array}$ & $\begin{array}{l}\text { F36 } \\
\text { M8 } \\
\text { F44 } \\
\text { M27 }\end{array}$ & $\begin{array}{l}88 \cdot 4 \\
86 \cdot 4 \\
92 \cdot 0 \\
91.0\end{array}$ & $\begin{array}{r}714 \\
1290 \\
122 \\
817\end{array}$ & $\begin{array}{l}\text { O467 } \\
1077\end{array}$ & $\begin{array}{l}\text { F48 } \\
\text { F22 }\end{array}$ & $\begin{array}{l}87 \cdot 0 \\
93 \cdot 1\end{array}$ & $\begin{array}{l}431 \\
783\end{array}$ \\
\hline \multicolumn{3}{|c|}{$\begin{array}{l}\text { Average resistance } \\
\text { Average for remainder } \\
\text { of group }\end{array}$} & $\begin{array}{r}144 \\
85\end{array}$ & \multicolumn{3}{|c|}{$\begin{array}{l}\text { Average resistance } \\
\text { Average for remainder } \\
\text { of group }\end{array}$} & $\begin{array}{r}736 \\
52\end{array}$ & \multicolumn{3}{|c|}{$\begin{array}{l}\text { Average resistance } \\
\text { Average for remainder } \\
\text { of group }\end{array}$} & $\begin{array}{l}607 \\
165\end{array}$ \\
\hline
\end{tabular}


oxygen, and confirms that the low saturation was due primarily to poor oxygenation of the blood, and not to an intracardiac shunt. The fourth (Case 0900) had occasional moist sounds at both bases, so that in this case the difficulty in oxygenation may have been related to exudate rather than changes in the vessel walls.

In the atrial septal defect group, the correlation between unsaturation and increased resistance is very striking, the average resistance for these 4 cases being 736 per cent, as compared with 52 per cent for the remainder of the group.

Two cases of ventricular septal defect show a reduction in arterial saturation, and these two again show a level of resistance far in excess of the average for the remainder of the group (607 per cent as compared with 203 per cent). In Case 0467, the pulmonary nature of this change was confirmed by a dramatic increase of saturation to the normal level following administration of oxygen. In Case 1077, no conclusive evidence of a pulmonary origin of the unsaturation is available.

\section{Discussion}

The results presented above show that in several forms of acyanotic congenital heart disease with a left-to-right shunt there may be an increase of pulmonary arterial pressures. However, the relative incidence of hypertension appears to be lower in the patent ductus group than in the groups with atrial and ventricular septal defects.

There is little difference between the average size of the shunt in the three conditions, and the high incidence of hypertension in ventricular septal defect seems related largely to the nature of the defect. The difference between patent ductus and atrial septal defect may be attributable in part to the older age of the latter group when submitted for catheterization. Patent ductus presents a clearly defined clinical picture which is fairly readily recognized at routine examination, and is presented for surgical correction at an early age. On the other hand, atrial septal defect often presents comparatively trivial signs, and may pass unrecognized in childhood. The pulmonary vascular tree therefore tends to be exposed to the left-to-right shunt for a longer period before reference to hospital, and there is a correspondingly greater opportunity for the development of changes in the structure of the pulmonary vessels leading to a reduction in pulmonary flow and a gross increase in pulmonary arterial pressures. However, there does seem some justification for the view that the incidence of hypertension is less in patent ductus arteriosus, even if account is taken of the age of this group.

There has been considerable discussion concerning the ætiology of pulmonary hypertension. Some have regarded it as a persistence of the primary fotal hypertension, but while isolated cases of this type can be collected (Cosh, 1953), the present findings support the view that most cases develop in adult life. It has also been suggested that the increase in pulmonary arteriolar resistance represents a physiological spasm of the vessels which develops as a protective mechanism against the increased pulmonary flow. However, if the change were physiological in type, it would be expected to occur more uniformly in patients subjected to a left-to-right shunt.

Further, where the condition is surgically corrected, as in ligation of a ductus, restoration of normal pressures would be expected, whereas we have found that in two cases of patent ductus with severe hypertension, ligation actually increased the immediate pressure in the pulmonary artery. One showed a pressure of $86 / 76 \mathrm{~mm}$. $\mathrm{Hg}$ before and 93/79 $\mathrm{mm}$. $\mathrm{Hg}$ after closure of the ductus. The other showed a pressure of $47 / 35 \mathrm{~mm}$. $\mathrm{Hg}$ before and $74 / 52 \mathrm{~mm}$. $\mathrm{Hg}$ after closure.)

Finally, if the increase in resistance is a physiological protective mechanism, there is no obvious reason why it should be withheld until early adult life. Thus it seems far easier to understand the increase in resistance observed in the present series as a progressive anatomical change. In early childhood there is a passive dilatation of the pulmonary vessels in response to the increased flow, but later, probably as a response to this prolonged dilatation, the typical changes described by the morbid anatomists appear (Old and Russell, 1950; Symmers, 1952). These changes bring about 
a reduction in pulmonary flow despite an increase in pulmonary arterial pressure, and there is an associated difficulty in the oxygenation of the blood which produces a moderate unsaturation of the pulmonary venous and systemic arterial specimens.

The low incidence of such changes in patent ductus arteriosus despite large left-to-right shunts is not easy to understand; it may be related to the fact that in patent ductus the increased flow is distributed throughout the cardiac cycle, whereas in atrial septal defect and ventricular septal defect the increase is concentrated in the systolic phase (Campbell, 1951).

\section{SUMMARY}

Pressure flow relationships in the pulmonary artery have been examined in 55 patients, 24 with patent ductus arteriosus, 17 with atrial septal defect, and 14 with ventricular septal defect.

The pulmonary arterial pressure is normal in 10 cases of patent ductus, slightly increased in 6 and moderately increased in 6 cases. In the atrial and ventricular septal defect groups, the proportion showing hypertension is greater. In the atrial septal defect group the pressure is normal in 5 , slightly increased in 1 , moderately increased in 2 , and severely increased in 3 cases. In the ventricular septal defect group the pressure is normal in 2, slightly increased in 2 , moderately increased in 3, and severely increased in 7 cases: generally the systolic pressure corresponds fairly closely with the left ventricular systolic pressure unless the septal defect is small.

In all three conditions, the systolic pressure in the pulmonary artery may be a few $\mathrm{mm} . \mathrm{Hg}$ less than the right ventricular systolic reading: it is difficult to explain this discrepancy in terms of "relative stenosis" of the pulmonary valve, and the pressure difference is perhaps related to changes in the elastic properties of the dilated pulmonary artery.

The magnitude of the left-to-right shunt is similar in all three conditions, and cannot explain the differing incidence of hypertension.

The pressures in the ventricular septal defect group are high on account of the nature of the defect. In the atrial septal defect group, the higher pressures are probably due in part to the greater average age of this group, and in part to the concentration of the increased flow in the systolic phase of the cardiac cycle.

The pulmonary arteriolar resistance may be low, normal, or high in all forms of left-to-right shunt. If the patient is very young, a resistance below the normal value may be expected, but with increasing age, the resistance tends to be increased to values grossly above the normal. This is in keeping with the progressive development of anatomical changes in the pulmonary arteries producing narrowing of the lumen and impairment of oxygenation of the blood.

I wish to record my appreciation of the encouragement and assistance that Dr. Campbell has given during the preparation of this paper, and also thank him for permission to report details of a number of his cases. Other patients were under the care of Dr. Baker, Mr. Brain, and Mr. Brock, and my thanks are due to them for the use of their case records. I am also indebted to the Department of Medical Photography and Illustration, Guy's Hospital, for preparing the figures for publication.

\section{REFERENCES}

Adamo, F., Diehl, A., Jorgens, J., and Veasy, L. (1952). J. Pediat., 40, 49.

Bouchard, Fr., Rubio, V., and Limon, R. (1951). Arch. Mal. Coeur., 44, 550.

Campbell, M. (1951). Brit. Heart J., 13, 438.

Cosh, Ja. (1953). Brit. Heart J., 15, 423.

Cournand, A. (1950). Circulation, 2, 641.

Deuchar, D. C., and Knebel, R. (1952). Brit. Heart J., 14, 225.

Dexter, L., Dow, J. W., Haynes, F. C., Whittenberger, J. L., Ferris, B. G., and Hellems, H. K. (1950). J. clin. Invest., 29, 602 .

Dow, J. W., and Gorlin, R. (1950). Fed. Proc., 9, 33.

Eppinger, E. C., Burwell, G. S., and Gross, R. E. (1941). J. clin. Invest., 20, 127.

Fowler, N. O., Westcott, N., and Scott, R. C. (1953). Amer. Heart J., 46, 264.

Hansen, T. (1949). Acta. physiol. Scand., 19, Supp. 68.

Hellems, H. K., Haynes, F. W., and Dexter, L. (1949). J. Appl. Physiol., 2, 24.

Hickham, J. B., Cargill, W. H., and Golden, A. (1948). J. clin. Invest., 27, 290. 2B 
Holling, H. E., and Zak, G. (1950). Brit. Heart J., $12,153$.

Hultgren, H., Salzar, A., Purdy, A., Holman, E., and Garbode, F. (1953). Circulation, 8, 15.

Lagerlof, H., and Werkö, L. (1949). Scand. J. Clin. Lab. Invest., 1, 147.

Lurie, P., Gray, F., and Whittemore, R. (1952). Angiology, 3, 98.

Old, J., and Russell, W. (1950). Amer. J. Path., 26, 789.

Pedersen, A., and Warburg, E. (1952). Cardiologia, 21, 517.

Riley, R. L., Himmelstein, A., Motley, H. L., Weiner, H. M., and Cournand, A. (1948). Amer. J. Physiol., 152, 372.

Storstein, O., Humerfelt, S., Muller, O., and Rasmussen, H. (1952). Acta. med. Scand., $141,419$.

Symmers, W. (1952). J. clin. Path., 5, 36.

Taylor, B. E., Pollack, A. A., Burchell, H. B., Clagett, O. T., and Wood, E. H. (1950). J. clin. Invest., $29,745$.

Visscher, M. B., and Johnson, J. A. (1953). J. Appl. Physiol., 5, 635.

Voci, G., Touche, M., and Joly, Fr. (1951). Arch. Mal Coeur, 44, 1103.

Wood, P. (1950). Brit. med. J., 2, 639. 